\title{
Fluoride content of powdered infant formula meets Australian Food Safety Standards
}

Helen Clifford (author for correspondence: Queensland Health, PO Box 267, Southport, QLD 4215. Fax: (07) 5528 1681; e-mail: helen_clifford@health.qld.gov.au), Henry Olszowy, Megan K Young, John Hegarty, Matthew Cross

\begin{abstract}
Objectives: To identify the fluoride content of powdered formula for infants 0-12 months in products available from Brisbane stores in 2006/2007 and compare this with the fluoride content of infant formula products available in Australia 10 years earlier. To present results in a format to allow easy calculation of individual infants' estimated daily intakes.
\end{abstract}

Methods: A range of available infant formula powders were collected from major supermarkets and chemists in Brisbane, Queensland. The fluoride levels in infant formula powder samples were determined using a modification of the micro-diffusion method of Silva and Reynolds ${ }^{1}$ utilising perchloric acid and silver sulphate and measured with an ion selective (fluoride) electrode/meter. Fluoride content both prior to and after reconstitution, as well as estimated daily intake according to age was calculated.

Results: Formula samples contained an average of $0.49 \mu \mathrm{g} \mathrm{F} / \mathrm{g}$ of powder (range $0.24-0.92$ $\mu \mathrm{g} \mathrm{F} / \mathrm{g}$ ). After reconstitution with water containing $0 \mathrm{mg} / \mathrm{L}$ fluoride, the fluoride content averaged $7.09 \mu \mathrm{g} \mathrm{F} / 100 \mathrm{~mL}$ (range 3.367 - $22.72 \mu \mathrm{g} \mathrm{F} / 100 \mathrm{~mL}$ ). Estimated infant fluoride intakes ranged from $0.0039 \mathrm{mg} / \mathrm{kg} /$ day for a 6-12 month old infant when reconstituting milkbased formula with non-fluoridated water $(0 \mathrm{mg} / \mathrm{L})$, to $0.1735 \mathrm{mg} / \mathrm{kg} / \mathrm{day}$ for a $0-3$ month old infant when reconstituting soy-based formula with fluoridated water $(1.0 \mathrm{mg} / \mathrm{L})$. 
Conclusions: Infant formula powders contain lower levels of fluoride than previously found in Australia in 1996.

Implications: This confirms that infants consume only a small amount of fluoride from milkbased powdered infant formula. Although soy-based infant formulas contain more fluoride than milk-based products, the levels still comply with national food standards.

Keywords: Fluoride, infant formula, oral health, water fluoridation, fluorosis, dental, microdiffusion, ion selective electrode. 


\section{Introduction}

There are numerous guideline values for the level of exposure to fluoride that maximises health benefits (tooth decay prevention) and minimises adverse effects (dental fluorosis)., ${ }^{2,3,4}$ In Australia, 64\% of children experience tooth decay (dental caries) which causes concerns from mild discomfort through to debilitating pain as well as reduced capacity to chew, talk and smile. In comparison, approximately $22 \%$ of children experience some form of dental fluorosis. ${ }^{9,17}$ Dental fluorosis is mottling of teeth which may result from excessive fluoride being ingested while teeth are developing and may be of aesthetic concern. The NHMRC dietary guidelines for Australia and New Zealand, recommend fluoride adequate intake (AI) for infants which ranges from $0.01 \mathrm{mg} /$ day (birth to 6 months) to $0.5 \mathrm{mg} /$ day ( 7 to $12 \mathrm{months}$ ). The upper limit (UL) is $0.7 \mathrm{mg} /$ day and $0.9 \mathrm{mg} /$ day, respectively. ${ }^{3}$ Other authors have also reported guidance values 0.05 - $0.07 \mathrm{mg} \mathrm{F} / \mathrm{kg}$ body weight/day and UL's of up $0.10 \mathrm{mg}$ F/kg body weight/day. ${ }^{1,4,5}$

In recent years it has become widely accepted that little pre eruptive benefit to tooth enamel is achieved through the ingestion of fluoride, as the majority of benefit occurs from frequent exposure of the tooth enamel to fluorides post eruption. ${ }^{6}$ Therefore, benefit from fluoride will not begin until the first teeth erupt, at about 6 months of age at which time fluoride intake may come from an increasing variety of sources with the introduction of solid foods. Risk from excess fluoride ingestion in the first twelve months has been shown to have an association with deciduous teeth but not with permanent teeth as the critical period in which permanent teeth are most vulnerable does not begin until 15-21 months of age. ${ }^{7,8}$ This is supported by recent studies which show that reconstitution of infant formula with fluoridated water at $1 \mathrm{mg} / \mathrm{L}$ has little impact on fluorosis levels of permanent teeth, compared to other sources of fluoride ingestion, such as toothpaste ingestion and fluoride supplement use. ${ }^{9,10}$ Despite lack of 
agreement on guideline values and varying units of measurement, fluoride intake from infant formula has been frequently identified as a potential source of excess fluoride for infants depending on production processes and fluoride concentration of water used for reconstitution. ${ }^{4,7,11}$

In 1996, Silva and Reynolds investigated fluoride concentrations in infant formula in Australia and found that, when water fluoridated at $1 \mathrm{mg} / \mathrm{L}$ was used to reconstitute their formula samples, all exceeded their suggested UL of fluoride intake. In 1999, the NHMRC made a recommendation to develop a strategy to reduce excessive intake of fluoride from infant formula in Australia. ${ }^{6}$ The Australia New Zealand Food Standards Code was amended to include mandatory dental fluorosis risk labelling of powdered or concentrated infant formula if it contains more than $17 \mu \mathrm{g}$ F/100 kilojoules $(\mathrm{kJ})$ prior to reconstitution. ${ }^{12}$ Since that time there has been no reported investigation of the levels of fluoride in powdered or concentrated infant formula products commercially available in Australia. This study sought to redress this deficit.

\section{Methods}

One tin of every infant formula that was present on the shelves of two different major supermarkets in Brisbane was purchased in March 2006. Where possible a different batch number was obtained in another two stores of the same supermarket chain to achieve a sample of 33 different infant formula products. Two Chemist chain stores were also accessed to identify other common brands and different batches of products (June 2007). This produced a total sample of 53 tins of infant formula powder (15 products were double sampled, 1 triple sampled and 1 had four samples). Product labels identified country of manufacture as New Zealand, Ireland/Singapore, France/Germany/Netherlands and Australia. 
Fluoride in the infant formula powders was determined using a modification of the microdiffusion method of Silva and Reynolds utilising perchloric acid and silver sulphate. Square polystyrene Petri dishes with unvented lids to prevent loss of liberated hydrofluoric acid $(100 \mathrm{~mm} \times 100 \mathrm{~mm} \times 18 \mathrm{~mm})$ were used throughout this work and were pre-cleaned by soaking in 5\% perchloric acid overnight, rinsed with deionised water and oven dried prior to use.

Analytical Reagent (AR) grade perchloric acid and silver sulphate may contain low levels of fluoride as an impurity and must be processed to reduce the fluoride contamination to acceptable levels. This was achieved by $0.3 \mathrm{~g}$ finely ground silver sulphate and $14 \mathrm{~mL}$ of $48 \%$ perchloric acid (prepared by diluting concentrated $70 \%$ perchloric acid) was placed in a Petri dish and mixed with a stirring rod. The lid was placed slightly ajar on top of the Petri dish (to allow contaminant $\mathrm{HF}$ vapours to escape) and placed in an air oven at $50^{\circ} \mathrm{C}$ overnight. After the heating process in the air oven overnight, the perchloric acid and silver sulphate was ready to use.

At least $12 \times 12$ drops of $0.5 \mathrm{M}$ sodium hydroxide solution were pipetted to the inside of the Petri dish lids using an 8 channel Finn-pipette, ensuring that the 144 drops were evenly spaced. The Finn-pipette was set so the volume of each drop was approximately $3.5 \mu \mathrm{L}$ resulting in a final volume of $0.5 \mathrm{M}$ sodium hydroxide spotted onto the lid of approximately $0.5 \mathrm{~mL}$. The lids were placed, with drops facing upwards, into a clean air oven for at least 2 hours to allow the moisture in the sodium hydroxide solution to evaporate.

A weight of $0.35 \mathrm{~g}$ of infant formula powder was transferred to the prepared (decontaminated) perchloric acid/silver sulphate mixture and covered with the spotted lid as quickly as possible. The mixture was evenly dispersed by swirling and then placed in a clean air oven at $50^{\circ} \mathrm{C}$ for 
20hrs. At the completion of the heating process, $1.5 \mathrm{~mL}$ deionised water and $1.5 \mathrm{~mL}$ TISAB reagent (total ionic strength adjustment buffer) was added to the Petri lid and manually swirled gently until all the crystals were dissolved (about 5 minutes per sample) as the solution does not entirely cover the bottom of the Petri lid. The $3 \mathrm{~mL}$ extract on the lid was then transferred into an acid washed $15 \mathrm{~mL}$ HDPE plastic tube and the screw cap was fixed to avoid contamination. The fluoride content in the $3 \mathrm{~mL}$ extract was then measured directly from the $15 \mathrm{~mL}$ HDPE plastic tube using the ISE electrode/meter. Three certified reference materials (CRM) were used during this study and provided the following results for fluoride; NCS DC 73350 (powdered poplar leaves): requires $22 \pm 4 \mathrm{mg} / \mathrm{kg}$, found $20 \pm 0.5 \mathrm{mg} / \mathrm{kg}$; Lypocheck Urine (Ref 405, Lot69112): requires $7.7 \pm 0.4 \mathrm{mg} / \mathrm{L}$, found $7.7 \pm 0.25 \mathrm{mg} / \mathrm{L}$; Seronorm Urine (Ref 201205, Lot 0511545): requires 4.0mg/L, found 3.7 $\pm 0.07 \mathrm{mg} / \mathrm{L}$.

Queensland Health formula feeding guidelines within the Personal Health Record ${ }^{13}$ were used to calculate the average consumption of reconstituted formula for $0-2$ months $(150 \mathrm{~mL} / 5.1 \mathrm{~kg} / \mathrm{day}=765 \mathrm{~mL} /$ day $), 3-6$ months $(120 \mathrm{~mL} / 7 \mathrm{~kg} / \mathrm{day}=840 \mathrm{~mL} /$ day $)$ and $7-12$ months $(110 \mathrm{~mL} / 809 \mathrm{~kg} / \mathrm{day}=979 \mathrm{~mL} / \mathrm{day})$.

\section{Results}

No samples tested were labelled as containing more than $17 \mu \mathrm{g}$ of fluoride per $100 \mathrm{~kJ}$ prior to reconstitution and results confirmed this. The median concentration of fluoride was $2.37 \mu \mathrm{g}$ $\mathrm{F} / 100 \mathrm{~kJ}$ (min-max 1.21 - 7.20) or $0.46 \mu \mathrm{g} \mathrm{F/g} \mathrm{(0.24} \mathrm{-} \mathrm{1.20)} \mathrm{in} \mathrm{milk-based} \mathrm{formula} \mathrm{powder} \mathrm{and}$ $5.15 \mu \mathrm{g}$ F/100kJ (min-max 2.46 - 8.11) or $1.015 \mu \mathrm{g}$ F/g (0.46 -1.60) in soy-based formula powder. When water with no fluoride was used for reconstitution, an average of 6.39 micrograms fluoride/100mL (SD 2.27) for milk-based formula and 14.53 micrograms fluoride/100mL (SD 8.66) for soy-based formula resulted. Comparing the findings of this 
study with the results of Silva and Reynolds, the average fluoride concentration of infant formula in Australia seems to have decreased, with milk-based formula containing about one third the fluoride content, and soy-based formula about half the fluoride content found in 1996. It should be noted that the current study included methodology to remove any fluoride impurities from the analytical reagent and therefore lower average fluoride levels might be expected compared to the Silva and Reynolds study.

The recommended volume of formula an infant consumes per day varies with age and weight. ${ }^{13}$ Table 1 shows that average fluoride intake per kilogram body weight per day from infant formula varies considerably by age; $0.009 \mathrm{mg} \mathrm{F} / \mathrm{kd} /$ day at age $0-2$ months down to $0.006 \mathrm{mg} \mathrm{F} / \mathrm{kg} /$ day at 6-12 months for milk-based products. The average contribution to daily fluoride intake from infant formula in milligrams of fluoride by average weight for age varied from 0.04 to $1.04 \mathrm{mg}$ F/day for milk-based formula and 0.11 to $1.12 \mathrm{mg}$ F/day for soy-based formula (Table 2). At levels of $0.7 \mathrm{mg} / \mathrm{L}$ of fluoride in water, estimates of intake identified in this study suggested intake exceeds guidance values but not UL values for all age groups. At water fluoride levels of $1 \mathrm{mg} / \mathrm{L}$, estimates exceeded both guidance values and the UL values for all age groups.

\section{Discussion}

Fluoride concentration in infant formula powder appears to meet Australian guidelines based on the samples used in this study; however infant formula products presented may not be representative of products available across Australia as samples were collected in Brisbane only. The results of this study are also limited to use of product as per manufacturer's recommendation and does not account for alternative use of products by consumers. Daily intake calculations are limited to similar total intake per day recommendation as those 
recommended by Queensland Health formula feeding guidelines and do not account for variations in feeding guidelines in other jurisdictions or personal preferences.

While none of the formula powders sampled demonstrated levels of fluoride in excess of FSANZ guidelines prior to reconstitution, calculations suggested that fluoride intake from powdered infant formula products in areas with $1 \mathrm{mg} / \mathrm{L}$ of fluoride or above in the water may exceed upper limits and therefore pose a risk of mild dental fluorosis.

This study aimed to estimate the amount of fluoride infants consumed from formula between birth and 12 months. This estimate is limited by the fact that National guidelines recommend breastfeeding exclusively from birth up to 6 months and that infants begin on solid food from 6 months of age with large variations in uptake. ${ }^{3}$ Since no infant formula usage rates are available for Australia, only an estimate can be made from Australian breastfeeding data (exclusive and supplemented). ${ }^{14}$ This would suggest that about $13 \%$ of infants at birth and up to $52 \%$ of infants at age 6 months are formula fed. However, given that the introduction of solids and drinking from cup also occurs around 6 months, $52 \%$ is likely to be an overestimate at 6 months of age and too much uncertainty exists to estimate formula use at 12 months of age.

While this research presents a more accurate picture of potential fluoride intake through infant formula consumption, it does not provide information on all sources of fluoride intake for these age groups. These findings are similar to overseas studies where the average intake for infants when formula is reconstituted with water at $1 \mathrm{mg} / \mathrm{L}$ fluoride have been estimated between 0.11 and $0.17 \mathrm{mg} \mathrm{F} / \mathrm{kg} / \mathrm{day}$, with the highest intakes being recorded at 2 weeks of age. ${ }^{11,15,16}$ Since studies have shown no evidence of benefit from fluoride until teeth erupt at 
about 6 months of age and evidence of mild fluorosis risk to baby teeth during this time has also been published, this study supports previous recommendations that water with $1 \mathrm{mg} / \mathrm{L}$ or more of fluoride not be used to reconstitute powdered infant formula, if a parent is concerned about a risk of their child experiencing mild fluorosis in baby teeth. ${ }^{7}$

While this study identifies that fluoride intake guidelines may be exceeded in some circumstances, there is insufficient evidence to confirm that the adequate and upper level intake values accurately depict the point at which the benefit of water fluoridation (protection from tooth decay) is outweighed by the risk (dental fluorosis) for children once the teeth begin to erupt. Further research and in-depth analysis of all variables contributing to risk and benefit, for varying infant ages, would be required to more accurately predict AI and UL values.

With this in mind, it is hoped that these findings allow community members and health professionals to more accurately calculate the potential intake of fluoride from infant formula, and encourage further research to establish a stronger evidence base for guideline values.

\section{Acknowledgements:}

The authors gratefully acknowledge the support of Queensland Health, Oral Health Unit and Forensic and Scientific Services. 
Table 1: Fluoride content of milk-based (MB) and soy-based (SB) infant formula when reconstituted with specified fluoride levels in the water for infants aged 0-12 months.

\begin{tabular}{|c|c|c|c|c|c|c|c|c|c|c|}
\hline \multirow[t]{2}{*}{$\begin{array}{l}\text { Fluoride } \\
\text { level in } \\
\text { water }\end{array}$} & & \multicolumn{3}{|c|}{$\begin{array}{c}0-2 \text { months }^{ \pm} \\
150 \mathrm{~mL} / \mathrm{kg} / \text { day } \\
\text { mg F/kg/day }\end{array}$} & \multicolumn{3}{|c|}{$\begin{array}{c}\text { 3-6 months }{ }^{ \pm} \\
120 \mathrm{~mL} / \mathrm{kg} / \text { day } \\
\mathrm{mg} \mathrm{F} / \mathrm{kg} / \text { day }\end{array}$} & \multicolumn{3}{|c|}{$\begin{array}{c}\text { 7-12 months }{ }^{ \pm} \\
110 \mathrm{~mL} / \mathrm{kg} / \text { day } \\
\mathrm{mg} \mathrm{F} / \mathrm{kg} / \text { day }\end{array}$} \\
\hline & & median & $\min$ & $\max$ & median & $\min$ & $\max$ & median & $\min$ & $\max$ \\
\hline \multirow[t]{2}{*}{$0.0 \mathrm{mg} / \mathrm{L}$} & MB: & 0.009 & 0.005 & 0.020 & 0.007 & 0.004 & 0.016 & 0.006 & 0.004 & 0.015 \\
\hline & SB: & 0.021 & 0.010 & 0.034 & 0.017 & 0.008 & 0.027 & 0.016 & 0.008 & 0.025 \\
\hline \multirow[t]{2}{*}{$0.2 \mathrm{mg} / \mathrm{L}$} & MB: & 0.039 & 0.040 & 0.050 & 0.031 & 0.030 & 0.040 & 0.028 & 0.030 & 0.040 \\
\hline & SB: & 0.051 & 0.040 & 0.060 & 0.041 & 0.030 & 0.050 & 0.038 & 0.030 & 0.050 \\
\hline \multirow[t]{2}{*}{$0.7 \mathrm{mg} / \mathrm{L}$} & MB: & 0.114 & 0.110 & 0.130 & 0.091 & 0.090 & 0.100 & 0.083 & 0.080 & 0.090 \\
\hline & SB: & 0.126 & 0.120 & 0.140 & 0.101 & 0.090 & 0.110 & 0.093 & 0.080 & 0.100 \\
\hline \multirow[t]{2}{*}{$1.0 \mathrm{mg} / \mathrm{L}$} & MB: & 0.159 & 0.160 & 0.170 & 0.127 & 0.120 & 0.140 & 0.116 & 0.110 & 0.120 \\
\hline & SB: & 0.171 & 0.160 & 0.180 & 0.137 & 0.130 & 0.150 & 0.126 & 0.120 & 0.130 \\
\hline
\end{tabular}

\pm Only products suitable for infants of this age are included in calculations. Quantity of reconstituted

infant formula consumed ( $\mathrm{mL} / \mathrm{kg} / \mathrm{day}$ ) based on Queensland Health formula feeding guidelines 2005 .

Table 2: Estimated fluoride intake from milk-based (MB) and soy-based (SB) infant formula when reconstituted with specified fluoride levels in the water for infants aged 0-12 months.

\begin{tabular}{llccc}
\hline $\begin{array}{l}\text { Fluoride } \\
\text { level in } \\
\text { water }\end{array}$ & & $\begin{array}{c}0-2 \text { months } \\
(5.1 \mathrm{~kg}) \\
\mathrm{mg} \mathrm{F} / \mathrm{day}\end{array}$ & $\begin{array}{c}3-6 \text { months } \\
(7 \mathrm{~kg}) \\
\mathrm{mg} \mathrm{F} / \text { day }\end{array}$ & $\begin{array}{c}7-12 \text { months } \\
(8.9 \mathrm{~kg}) \\
\mathrm{mg} \mathrm{F} / \text { day }\end{array}$ \\
\hline $0.0 \mathrm{mg} / \mathrm{L}$ & $\mathrm{MB}:$ & 0.04 & 0.05 & 0.06 \\
& $\mathrm{SB}:$ & 0.11 & 0.12 & 0.14 \\
\hline $0.2 \mathrm{mg} / \mathrm{L}$ & $\mathrm{MB}:$ & 0.20 & 0.22 & 0.25 \\
& $\mathrm{SB}:$ & 0.26 & 0.29 & 0.34 \\
\hline $0.7 \mathrm{mg} / \mathrm{L}$ & $\mathrm{MB}:$ & 0.58 & 0.64 & 0.74 \\
& $\mathrm{SB}:$ & 0.64 & 0.71 & 0.83 \\
\hline $1.0 \mathrm{mg} / \mathrm{L}$ & $\mathrm{MB}:$ & $0.81^{*}$ & $0.89^{*}$ & $1.04^{*}$ \\
& $\mathrm{SB}:$ & $0.87^{*}$ & $0.96^{*}$ & $1.12^{*}$ \\
\hline
\end{tabular}

*above UL (NHMRC 2005)

\section{References}

1. Silva M, Reynolds E. Fluoride content of infant formula in Australia. Aust Dent J. 1996; (41)1: 37-42.

2. Agency for Toxic Substances and Disease Registry [Website]. Toxicological profile for Fluorides, Hydrogen Fluoride, and Fluorine. United States, Department of Health and Human Services, Public Health Service. [Released September 2003; cited May 2008]. Available from: http://www.atsdr.cdc.gov/toxprofiles/tp11.pdf.

3. National Health and Medical Research Council (NHMRC). Food for Health: Dietary Guidelines for Australians. Canberra: Australian Government Department of Health and Ageing; 2005.

4. Buzalaf MA, Granjeiro JM, Damante CA, de Ornelas F. Fluoride content of infant formulas prepared with deionized, bottled mineral and fluoridated drinking water. $J$ Dent Child, 2001; 68(1):37-41. 
5. Burt BA. The changing patterns of systemic fluoride intake. J Dent Res. 1992; 71(5):1228-37.

6. National Health and Medical Research Council. Review of water fluoridation and fluoride intake from discretionary fluoride supplements (ARCHIVED). Melbourne: NHMRC; 1999.

7. Marshall T. Levy S. Warren J. Broffitt B. Eichengerger-Gilmore J. Stumbo P. Associations between intakes of fluoride from beverages during infancy and dental fluorosis of primary teeth. J Amer Col Nut 23(2): 108-16, 2004 Apr.

8. Browne D. Whelton H. O'Mullane D. Fluoride metabolism and fluorosis. (Review). Journal of Dentistry. 33(3):177-86, 2005 Mar.

9. Spencer J, Do L. Changing risk factors for fluorosis among South Australian children. Com Dent and Oral Epi. 2007.

10. Anderson WA, Pratt I, Ryan MR, Flynn A. A probabilistic estimation of fluoride intake by infants up to the age of 4 months from infant formula reconstituted with tap water in the fluoridated regions of Ireland. Caries Res. 2004; 38(5):421-9.

11. Levy S, Kohout F, Guha-Chowdhury N, Kiritsy M, et al. Infants' fluoride intake from drinking water alone, and from water added to formula, beverages, and food. J Dent Res 1995; 74:1399-1407.

12. Food Standards Australia and New Zealand. Standard 2.9.1 Infant Formula Products. Canberra: FSANZ, 2008 [cited April 2008] Available from: http://www.foodstandards.gov.au/_srcfiles/Standard_2_9_1_Infant_Formula_Products _v95.pdf

13. Queensland Health. Personal Health Record. Brisbane: Queensland Health; 2005.

14. Australian Bureau of Statistics [Website]. Breastfeeding in Australia, 2001. [Released 17/09/2003; cited 2009 July1]. Available from: http://www.abs.gov.au/ausstats/abs@.nsf/cat/4810.0.55.001

15. Fomon S, Ekstrand J. Fluoride intake by infants. J Public Health Dent 1999; 59(4):229-341.

16. Erdal S, Buchanan S. A quantitative look at fluorosis, fluoride exposure, and intake in children using a health risk assessment approach. Environ Health Perspect 2005; 113(1):111-7.

17. Armfield J. Slade G. Spencer J. Water fluoridation and children's dental health. The Child Dental Health Survey, Australia 2002. Available from: http://www.arcpoh.adelaide.edu.au/publications/report/statistics/html files/cdhs2002.pdf 